\title{
Investigation and fuzzy logic prediction of the effects of clearance on the banking process of CuZn30 sheet metal
}

\author{
O. Çavuşoğlu*, H. Gürün \\ Gazi University, Faculty of Technology, Department of Manufacturing Engineering, Ankara 06500, Turkey
}

Received 25 July 2014, received in revised form 16 April 2015, accepted 16 April 2015

\begin{abstract}
In this study, the effects of sheet thickness and the punch-die clearance for blanking CuZn30 sheet material have been investigated experimentally, and estimations through fuzzy logic have been developed for those parameters affecting product quality. $1 \mathrm{~mm}$ and $2 \mathrm{~mm}$ thick $\mathrm{CuZn30}$ sheet materials were used in the experiments. Blanking experiments were carried out by manufacturing a modular die that had six different clearance values $(0.08 \mathrm{~mm}, 0.10 \mathrm{~mm}$, $0.12 \mathrm{~mm}, 0.14 \mathrm{~mm}, 0.16 \mathrm{~mm}$, and $0.18 \mathrm{~mm})$. Blanking forces were determined using a load cell during the experiments. Consequently, in blanking operations, burr height increases with increasing clearance while blanking force and the smooth shear fracture rate decrease with increasing clearance.
\end{abstract}

K e y w or d s: sheet metal, blanking, clearance, fuzzy logic, CuZn30

\section{Introduction}

$\mathrm{CuZn} 30$ sheet material is widely used today, especially in the electronics industry. While copper in its content provides high electrical and thermal conductivity, good wearing, and corrosion resistance, on the other hand, zinc also provides strength and hardness properties $[1,2]$.

Blanking is one of the most widely used sheet metal forming processes. This process is a general method that occurs by separating a part of the determined profile using a punch without metal being removed from the sheet material [3-5]. During this process, it is necessary to leave a certain amount of clearance between the punch and die. The amount of clearance affects die life, blanking force, and measurement accuracy by having an important role in the blanking process [6]. Furthermore, punch speed, the mechanical properties of the material, sheet thickness, contact and friction conditions are the other factors which affect product quality and the blanking process in blanking operations of sheet metal materials $[3,7,8]$.

The blanking process is shown in Fig. 1. The blanking process consists of three stages: elastic deformation, plastic deformation, and fracture. The first stage is the zone of elastic deformation that is formed by the contact of punch to sheet material. The second stage of blanking process occurs when the elastic limits of the material are exceeded at the beginning of punch penetration in the zone of plastic deformation. Continuation of punch penetration and increased force result in the third stage of the blanking process. A fracture event occurs starting with fractures on the sheet material $[7]$.

The most important factor affecting product quality and blanking process in blanking operations of sheet metal materials is the clearance value between a punch and die. The clearance value affects parameters such as die life, blanking force, measuremental precision as well as smooth sheared zone, fracture length and burr height (Fig. 2) which identify the quality of the finished product. Therefore, the most optimal clearance value should be selected in the blanking process of sheet metal materials. Giving small clearance value increases blanking force while decreasing die life. Contrary to this, giving more clearance value reduces product quality by causing a reduction of smooth sheared zone length and an increase in burr height. This value varies depending on sheet thickness and mechanical properties of sheet material to be cut [6].

*Corresponding author: tel: +90 (312) 20287 18; e-mail address: onurcavusoglu@gazi.edu.tr 


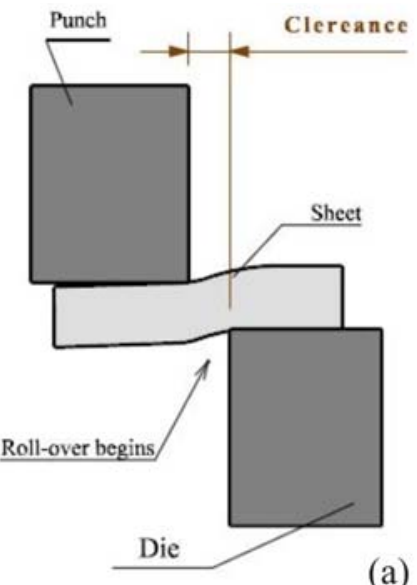

(a)

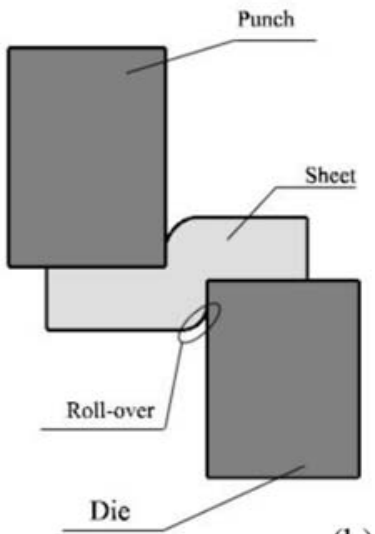

(b)
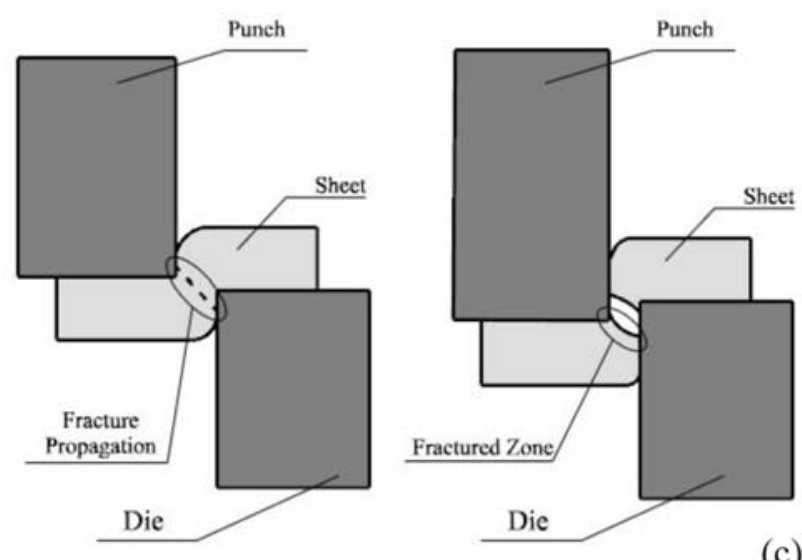

(c)

Fig. 1. Stages of blanking operation [3].

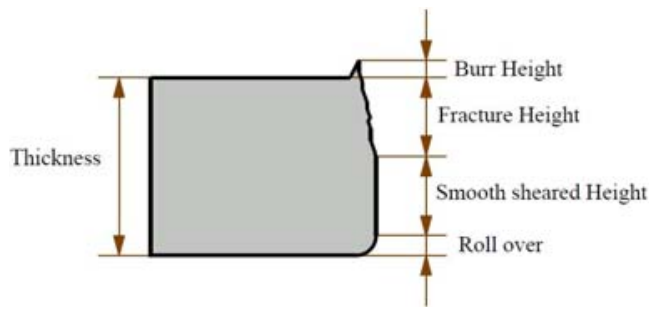

Fig. 2. Blanked product section.

Also, stress and abrasion of a die should be minimized by determining the most optimal clearance value by reason of the fact that the clearance value affects the die life as well as product quality [9].

When studies that were done thus far have been analysed, it is found that there are experimental and analytical research results. Through the finite elements method, Faura et al. attempted to determine the most optimal clearance value in the blanking process by using analytical methods [4]. Broken areas were examined during blanking operations by numerical modelling in a computer environment [5]. Tekiner et al. [6] investigated the impact of clearance on product quality by using aluminium sheet materials in different thicknesses. Samuel carried out blanking simulations and compared their results with experimental results in his study [7]. Husson and others examined the impact of blanking parameters for copper sheet material on the quality of blanking surfaces in their study [8]. To increase tool life, Subromonian et al. increased the optimal clearance value by performing blanking operations with different clearance values in their studies [9]. Shuqin et al., in their studies, examined the impact of clearance in the blanking process of $\mathrm{AlMg} 4.5 \mathrm{Mn} 0.4$ sheet material using experimental and the finite elements method [10]. Nowadays, based on the experimental results, estimations are developed by methods such as fuzzy logic or artificial neural networks for different parameter values. Hambli, in his study, examined the impact of the clearance and punch coating on burr height, and developed estimations through the artificial neural networks method [11].

It is seen that many studies have been done in varied thickness for different clearance and materials. However, when the literature had been reviewed, it was determined that there was not any study that examined the impact of clearance for CuZn30 materials on the blanking operation.

In this study, blanking and fracture rates were experimentally studied depending on the thickness of sheet material and the clearance, burr height and change of blanking forces. In parallel with this purpose, a modular die that holds six different clearances $(0.08,0.10,0.12,0.14,0.16$ and $0.18 \mathrm{~mm})$ with a punch of $20 \mathrm{~mm}$ in diameter, was manufactured. Blanking tests were carried out on $\mathrm{CuZn} 30$ sheet material 1 and $2 \mathrm{~mm}$ thick. Force measurements during the blanking process were performed using a load cell. Products obtained were examined using optical microscopy; smooth shear fracture rate and burr height were determined. Also, consistency with the experimental results was studied by performing fuzzy logic estimations.

\section{Material and method}

\subsection{Material}

CuZn30 sheet material 1 and $2 \mathrm{~mm}$ thick was used for the purpose of experimental tests. Chemical composition and mechanical properties of CuZn30 sheet material are given in Table 1. A modular die that holds six different clearances was manufactured to conduct the experiments. 1.2379 steel was used as the 
Ta ble 1. Chemical composition and mechanical properties of CuZn30

\begin{tabular}{cccccc}
\hline \multicolumn{5}{c}{ Chemical composition of CuZn30 (Element, \%) } \\
\hline $\mathrm{Sn}$ & $\mathrm{P}$ & $\mathrm{Ni}$ & $\mathrm{Bi}$ & $\mathrm{Cu}$ & $\mathrm{Fe}$ \\
0.0302 & 0.0211 & 0.0221 & 0.0107 & 69.81 & 0.058 \\
\hline $\mathrm{Zn}$ & $\mathrm{Mn}$ & $\mathrm{Si}$ & $\mathrm{Al}$ & $\mathrm{Sb}$ \\
30.02 & 0.00554 & 0.00203 & 0.00584 & 0.00612 & 0.00837 \\
\hline Tensile strength & Yield strength & Elongation (\%) & Elastic modulus & Poisson's ratio & Density \\
\hline & & 32 & $110 \mathrm{GPa}$ & 0.375 & $8.53 \mathrm{~g} \mathrm{~cm}^{-3}$ \\
\hline
\end{tabular}

Table 2. Punch and die diameters

\begin{tabular}{ccccccc}
\hline Punch diameter $(\mathrm{mm})$ & 1 & 2 & 3 & 4 & 5 & 6 \\
\hline 20 & 20.08 & 20.10 & 20.12 & 20.14 & 20.16 & 20.18 \\
\hline
\end{tabular}

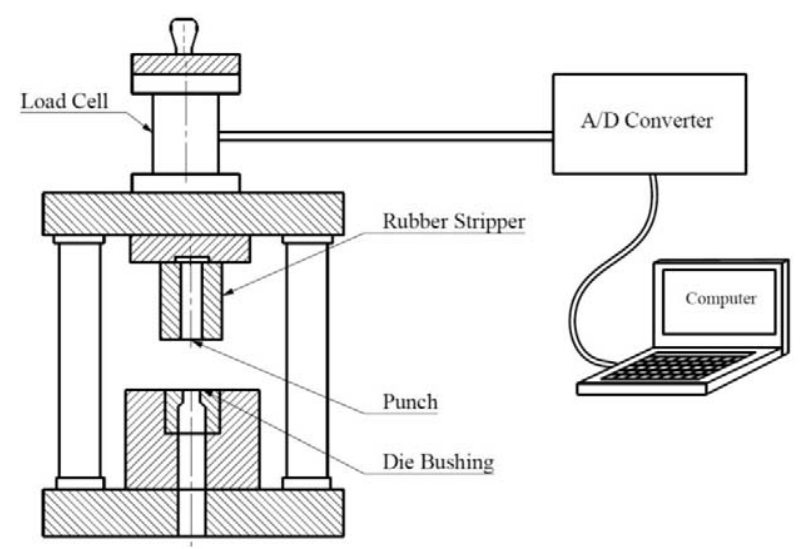

Fig. 3. Schematic overview of an experimental setup.

punch and die material. Die diameters are given in Table 2. Also, the experimental results were transferred through a load cell, read data card, amplifier and data display software into a computer environment.

\subsection{Blanking test}

The experimental setup that was used in the blanking test is shown in Figs. 3 and 4. A modular die that had six different clearances and two different sheet thicknesses was used for the experiments. A load cell with $240 \mathrm{kN}$ - capacity was used in the study conducted. Data reading speed was applied at 2000 data $s^{-1}$ for blanking operations. Measurements of blanking force were carried out during the blanking process utilizing the load cell used. Blanking tests were

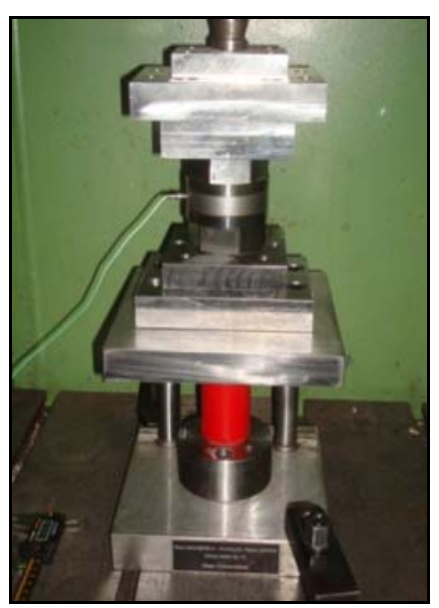

Fig. 4. Experimental setup.

performed at the same punch speed but with different clearances between a punch and die to consider the effect of the clearance on the blanking process. Totally, 90 blanking operations were performed by repeating each test five times to reduce error margin. Test samples obtained were examined at the magnification of $40 \times$ using an optical microscope, and smooth shear fracture rate and burr height were determined.

\subsection{Fuzzy logic system}

The fuzzy logic system was achieved by constructing a fuzzy logic rule table between input and output variables. Estimations of the lowest and highest values of the input variables in the fuzzy logic system were 
Ta b l e 3. X40 optical micrographs belonging to products sheared at different clearances for CuZn30 sheet material, $1 \mathrm{~mm}$ thick

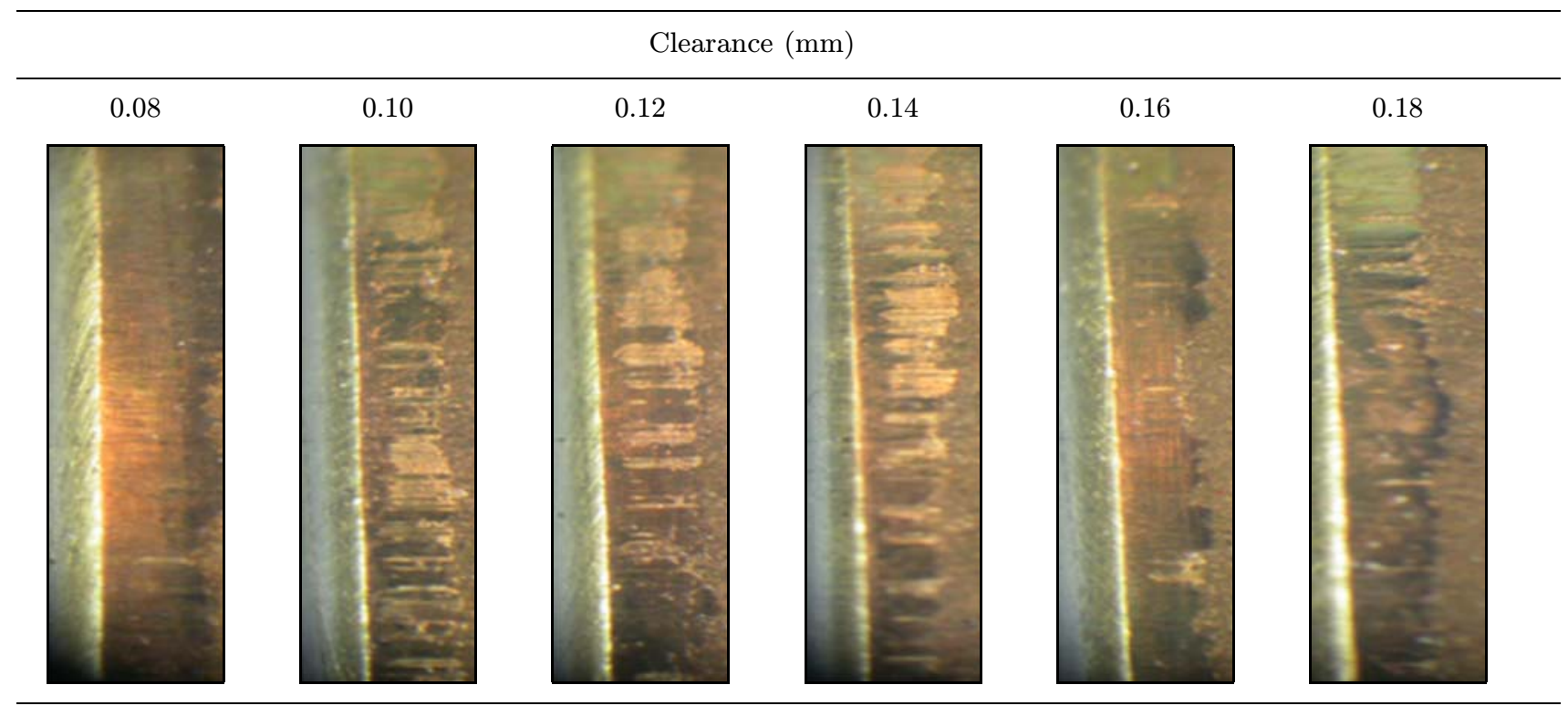

tested in a fuzzy logic programme. The fuzzy logic estimations obtained were compared with the experimental data.

In the system set, the clearance and sheet material thickness were indicated as input variables; burr height, blanking force and smooth shear fracture rate as output variables. The system was set with fuzzy logic rules that operated between input and output variables. The fuzzification unit converted numerical values in the input unit into fuzzy variables. A fuzzy inference process was used in the rule table, which included linguistic control rules. The outcomes of this rule table are linguistic variables. Also, the output unit reconverts these available linguistic variables into numerical values [12].

In the study, the triangular membership functions were used for transmission of the experimental results obtained from the experiments into the fuzzy logic system. Fuzzification methods were used in fuzzy systems such as membership functions, allocated variables, and fuzzy input. In this study, membership functions were used as the fuzzification method due to the conformability to system structure. It was studied by various decontamination methods, and the maximum membership method (Centre of Maximum, CoM) was indicated as the most appropriate decontamination method to the system.

Part of the experimental results was used in the training of the fuzzy logic system and the rest in the testing of the fuzzy logic system. Test results showed that experimental results were consistent with fuzzy logic estimations. Estimation values derived from the fuzzy logic system and experimental test results showed a maximum deviation of 0.01 percent.
By using the fuzzy logic system, blanking force, burr height and smooth shear depth were estimated for varied clearances and sheet material thickness.

\section{Results and discussion}

A total of 90 blanking operations were carried out on $\mathrm{CuZn30}$ sheet materials for six different clearances. In these tests, blanking forces were measured with the aid of a load cell, the sheared samples were examined using an optical microscope, and then mean burr heights and smooth shear fracture rates were determined. The photos taken from the samples $1 \mathrm{~mm}$ thick are given in Table 3 to serve as a model.

Fuzzy logic estimations were procured according to the experimental results obtained. Graphics of blanking force, burr height and shear fracture rate were created depending on experimental results and fuzzy logic estimations. Fuzzy logic systems can make estimations inside the range of experimental data. For that reason, during the creation of the graphics, 0.09, $0.11,0.13,0.15$ and $0.17 \mathrm{~mm}$ clearance values were used according to estimations derived from a fuzzy logic system in addition to $0.08,0.10,0.12,0.14,0.16$ and $0.18 \mathrm{~mm}$ clearance values used in experimental tests.

\subsection{Blanking force}

Force is the main factor to realize deformation in sheet metal forming operations. It is known that when clearance increases, blanking force always reduces [10]. In the experiment results, it was identified that when 


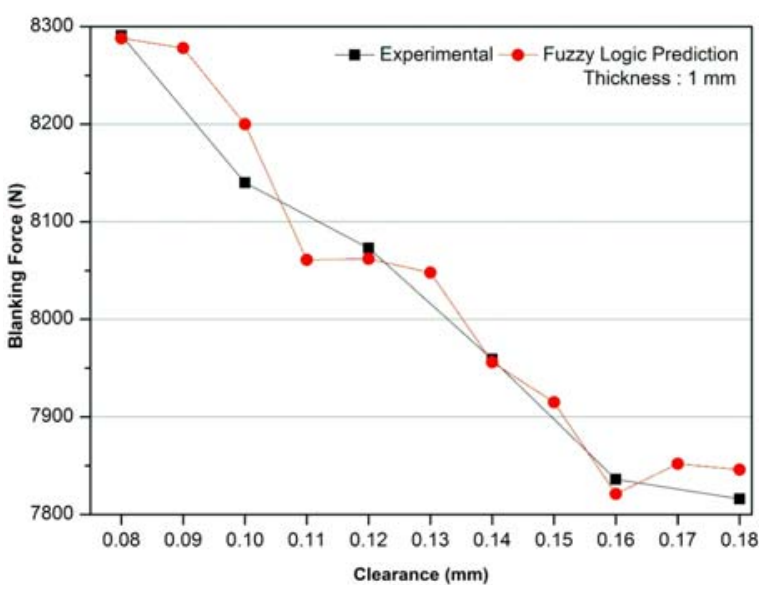

Fig. 5. Clearance - blanking force relation for sheet $1 \mathrm{~mm}$ thick.

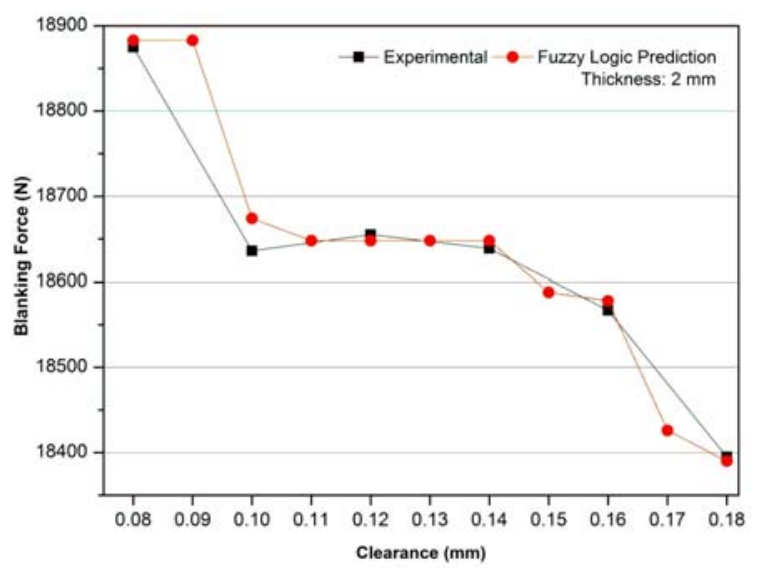

Fig. 6. Clearance - blanking force relations for sheet $2 \mathrm{~mm}$ thick.

the relationship between the obtained clearance and blanking force (Figs. 5, 6) was also studied, the blanking force was reduced depending on an increased clearance for both of two sheet thicknesses (1, $2 \mathrm{~mm})$.

The relationship between blanking force and punch penetration derived from tests that were carried out in the lowest and the highest clearance values used in experiments is shown on graphics in Figs. 7, 8. When graphics was analysed, it was observed that the blanking force needed in the smallest clearance value was higher. Besides, it was clear that the fracture stage occurred earlier by enhancing plastic deformation in large clearance values. Samuel's study [7] stated that increasing clearance value enhanced plastic deformation.

\subsection{Burr height}

An amount of unwanted material surplus accumu-

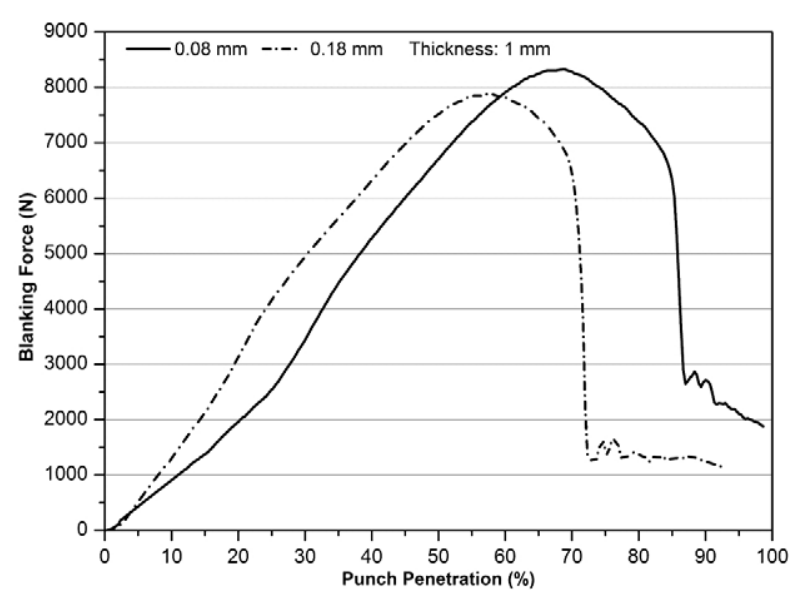

Fig. 7. Blanking force - punch penetration relation for minimum and maximum clearance and sheet $1 \mathrm{~mm}$ thick.

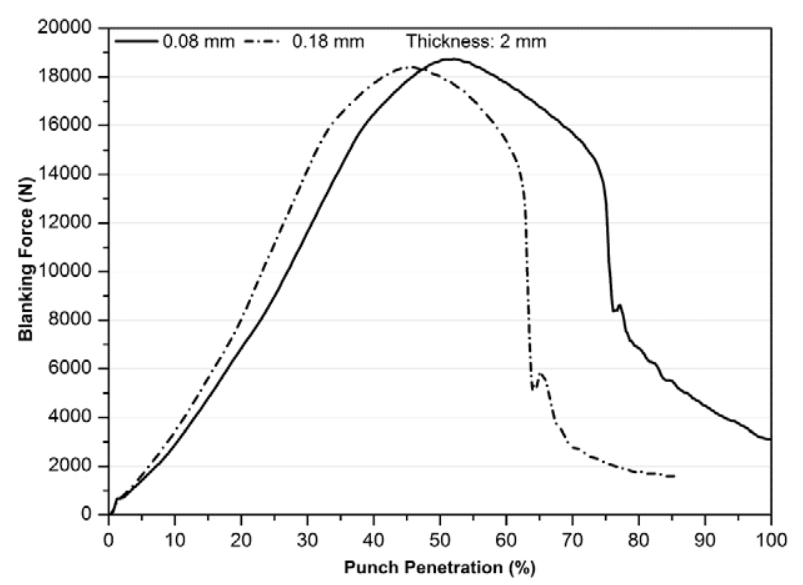

Fig. 8. Blanking force - punch penetration relation for minimum and maximum clearance and sheet $2 \mathrm{~mm}$ thick.

lates at the edges of the product according to the material's flow direction during the separation of the product from the sheet in blanking operations. This situation affects product quality negatively. In the study carried out, samples obtained in different clearance values were measured using an optical microscope. It was determined that burr height increased with increasing clearance (Figs. 9, 10). Also, burr height increased in direct proportion to increasing sheet thickness. In the study of Tekiner et al., it was reported that burr height increased with increasing clearance [6].

\subsection{Smooth sheared/Fracture rate}

High smooth shear fracture rate is required as a factor that improves the quality of the product obtained in blanking operations. The clearance affects this rate [8]. In the study carried out, the highest 


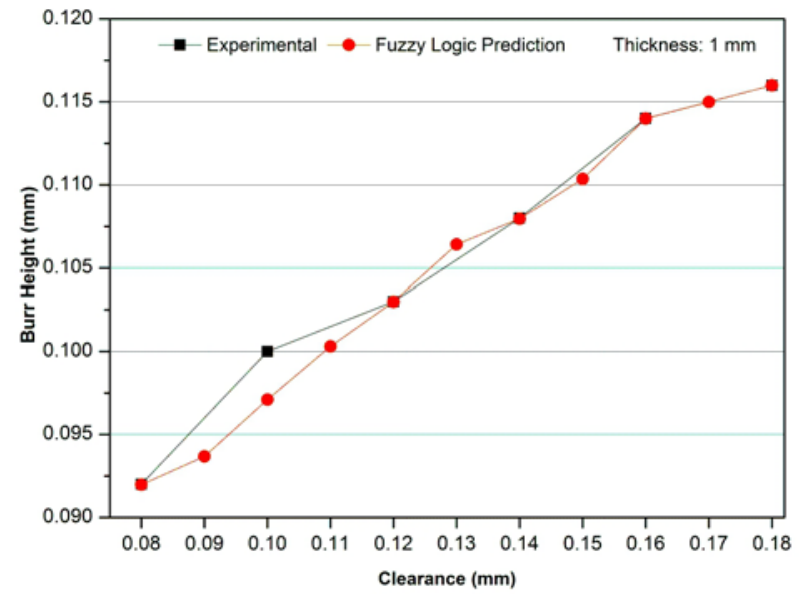

Fig. 9. Burr height - clearance relation for sheet $1 \mathrm{~mm}$ thick.

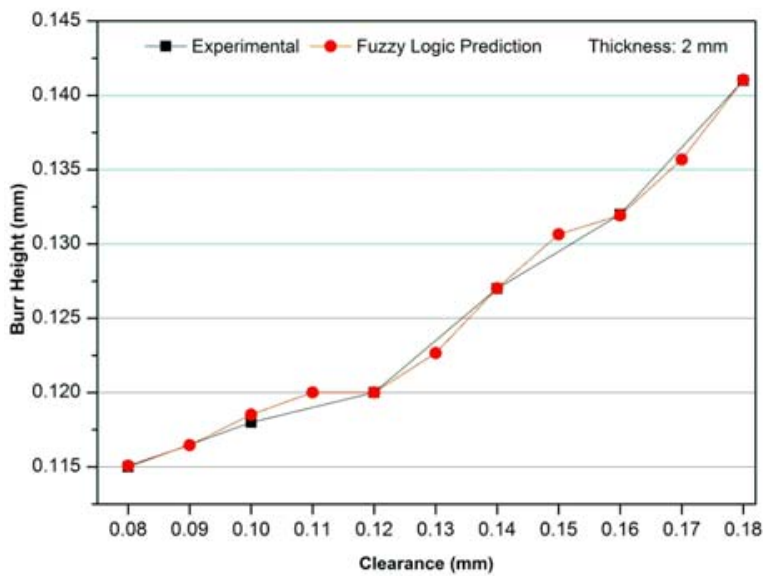

Fig. 10. Burr height - clearance relation for sheet $2 \mathrm{~mm}$ thick.

smooth shear fracture rate was procured in $0.08 \mathrm{~mm}$, the lowest clearance value. It was determined to be the cause of reducing smooth shear fracture rate along with increasing clearance values for both sheet thicknesses (Figs. 11, 12). Also, Tekiner et al. [6] stated that when the clearance reduced, the smooth shear fracture rate increased, and at this moment a product having a smoother surface could be obtained. In the study of Kwak et al., they indicated that smooth shear fracture rate reduces with increasing the clearance [13].

\section{Conclusions}

Blanking operations to CuZn30 sheet material in 2 different thicknesses were applied in different clearance values. Fuzzy logic estimations were developed in terms of the data obtained and the relations between

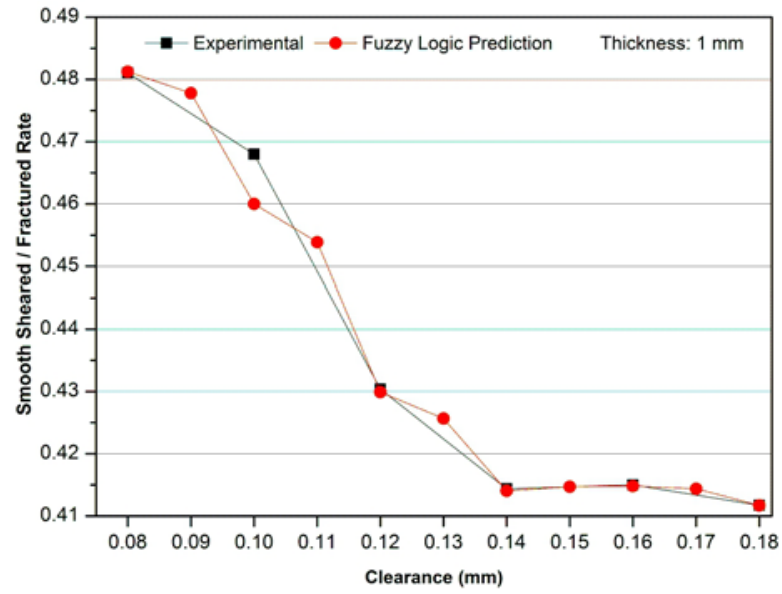

Fig. 11. Smooth shear fracture rate - clearance relation for sheet $1 \mathrm{~mm}$ thick.

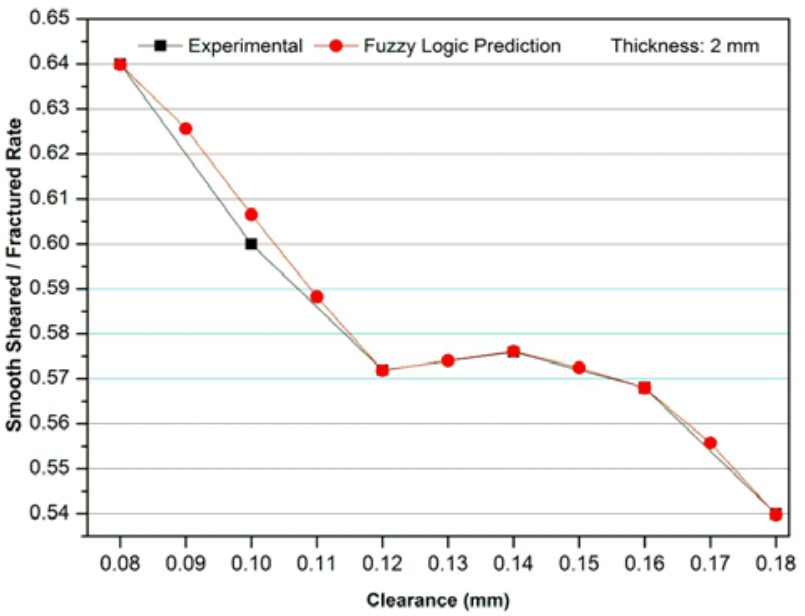

Fig. 12. Smooth shear fracture rate - clearance relation for sheet $2 \mathrm{~mm}$ thick.

blanking force, burr height and smooth shear fracture rate with clearance values for $\mathrm{CuZn30}$ sheet material were studied.

- It is confirmed again that the clearance affects the blanking process and the product.

- Increasing of clearance reduces blanking force and provides an earlier fracture occurrence.

- It was found that increasing the clearance enhanced burr height; on the other hand, it led to a decline in the smooth shear fracture rate. This situation negatively affects the quality of the product obtained. The lowest burr height and the highest smooth shear fracture rate value for $\mathrm{CuZn} 30$ sheet materials were procured for a $0.08 \mathrm{~mm}$ clearance value.

- The highest blanking force for a clearance value of $0.08 \mathrm{~mm}$ was also measured in the blanking operations for both of sheet thicknesses. The increase in the clearance value led to a decline in blanking forces. 
- When estimations were carried out by a fuzzy logic system and then compared with experimental data, it was found that an acceptable level of results was yielded.

\section{References}

[1] Gau, J.-T., Principe, C., Yu, M.: J. of Materials Processing Technology, 191, 2007, p. 7. doi:10.1016/j.jmatprotec.2007.03.035

[2] Unkü, B. S., Atik, E.: J. of Alloys and Compounds, 489, 2010, p. 262. doi:10.1016/j.jallcom.2009.09.068

[3] Miguel, V., Jr., Bressan, J. D.: J. of Materials Processing Technology, 125-126, 2002, p. 206. doi:10.1016/S0924-0136(02)00313-8

[4] Faura, F., García, A., Estrems, M.: J. of Materials Processing Technology, 80-81, 1998, p. 121. doi:10.1016/S0924-0136(98)00181-2

[5] Brokken, D., Brekelmans, W. A. M., Baaijens, F. P. T.: J. of Materials Processing Technology, 83, 1998, p. 192. doi:10.1016/S0924-0136(98)00062-4
[6] Tekiner, Z., Nalbant, M., Gürün, H.: Materials and Design, 27, 2006, p. 1134. doi:10.1016/j.matdes.2005.03.013

[7] Samuel, M.: J. of Materials Processing Technology, 84, 1998, p. 97. doi:10.1016/S0924-0136(98)00083-1

[8] Husson, C., Correia, J. P. M., Daridon, L., Ahzi, S.: J. of Materials Processing Technology, 199, 2008, p. 74. doi:10.1016/j.jmatprotec.2007.08.034

[9] Subramonian, S., Altan, T., Ciocirlan, B., Campbell, C.: Int. J. of Machine Tools \& Manufacture, 75, 2013, p. 63. doi:10.1016/j.ijmachtools.2013.09.004

[10] Shuqin, X., Hoogen, M., Pyttel, T., Hoffmann, H.: J. of Material Processing Technology, 122, 2002, p. 338. doi:10.1016/S0924-0136(01)01239-0

[11] Hambli, R.: Int. J. of Mechanical Sciences, 44, 2002, p. 2089. doi:10.1016/S0020-7403(02)00168-6

[12] Baykal, N., Beyan, T.: Fuzzy Logic Principles and Fundamentals. Ankara, Bıçaklar Kitabevi 2004. (In Turkish)

[13] Kwak, T. S., Kim, Y. J., Bae, W. B.: J. of Materials Processing Technology, 130, 2012, p. 462. doi:10.1016/S0924-0136(02)00767-7 